\title{
E-PETITIONING: ENABLING GROUND-UP PARTICIPATION
}

\author{
Nicholas J. Adams ${ }^{1}$, Ann Macintosh ${ }^{1}$ and Jim Johnston ${ }^{2}$ \\ 'International Teledemocracy Centre (ITC), Napier University, 10 Colinton Road, Edinburgh \\ EHIO 5DT, Scotland, UK, ${ }^{2}$ The Scottish Parliament, Edinburgh, Scotland, UK.
}

Abstract: This paper takes as background voter apathy and the emergence of petitions as a mechanism for political activity and considers the role of e-petitioning. It describes how an e-Petitioning System is being used to support the Scottish Parliament's four key principles of: sharing power; accountability; access and participation; and equal opportunities. It highlights the increasing uptake of epetitions and the gradual understanding of how the integrated discussion forum can be used to facilitate dialogue on issues raised.

We briefly describe the Scottish Parliament Petitions processes and outline the key features of the e-Petitioner System, before showing how the e-Petitioner supports these Parliamentary processes. With a wealth of experience gained through operating the e-Petitioner System successfully at a national level, we then describe how this facilitated the re-engineering of the System for the specific needs of two Local Authorities in England.

Key words: e-Petitioning, e-Government, Public Authority, Parliament, Local Government

\section{PROBLEM ADDRESSED}

In October 2004, 78 delegates from the parliaments of $22 \mathrm{EU}$ member countries attended the European Conference of Members of National Parliaments in Information and Communication Technologies (http://www.epri.org/epriweb/contents/introseite.php). The aim was to discuss how ICT could strengthen the importance of parliamentarians and parliaments. One of the main issues to emerge was the need to strengthen parliamentary democracy with better involvement of citizens in political and democratic processes. The conference also highlighted the decline in voter 
turnout at elections and general trends in increasing political apathy.

To counter political apathy and to re-engage the public the OECD report Citizens as Partners (2001) describes the urgent need for transparency, accountability and participation in political decision-making. It goes on to suggest three types of engagement strategies by which governments might meet this public demand. It states:

"Citizens can make an active and original contributions to policy-making, when their relationship with government is founded on the principle of partnership. Active participation represents a new frontier in governmentcitizen relations for all OECD Member countries." (p. 41)

Petitioning is one way to achieve active participation and indeed in many countries around the world, citizens have long used petitions to make their feelings known about issues that concern them. Simply, a petition is a formal request to a higher authority, e.g. parliament or other authority, signed by one or a number of citizens. However, the format of petitions and the way petitions are submitted and subsequently considered by parliaments varies greatly from country to country. It is therefore interesting to note that recent research conducted on behalf of the Electoral Commission in the UK (2005) found that apart from voting in elections, signing petitions is the most frequently undertaken political activity in the UK. MORI undertook the survey which involved interviews with a representative sample of 2,065 adults aged $18+$ across the UK. It reports that:

"The past 12 months have seen a statistically significant increase in the number who say they have signed a petition over the past two or three years (from 39\% in December 2003 to 44\% in December 2004)." (p. 17)

As such this paper takes as background voter apathy and the emergence of petitions as a mechanism for political activity and considers the role of epetitioning. It describes the increasing use of e-petitioning within the Scottish Parliament, which has accepted e-petitions since March 2000, and shows how the same e-Petitioner System is now in use in public authorities in England with only minor modifications to system functionality and associated political processes.

\section{PETITIONING AND THE SCOTTISH PARLIAMENT}

In July 1999 the Scottish Parliament was officially opened. This gave devolved power for specific areas of government from the Westminster Parliament in London to a new Scottish Parliament. One of the main 
documents setting out how the new Parliament should work was The Consultative Steering Group (CSG) report, Shaping Scotland's Parliament (HMSO 1999). This identified 4 key principles as the basis for the way which the Parliament should conduct its work and these were unanimously agreed by the Parliament in 1999:

- Sharing the Power

- Accountability

- Access and Participation

- Equal Opportunities.

In relation to access and participation the CSG in its final report states that: 'it will also be important to develop a culture of genuine consultation and participation if people in Scotland, particularly those who do not currently engage in the political process, are to be encouraged to participate.'

Integral to developing this culture was the establishment of a Public Petitions Committee (PPC) whose remit consists solely of the consideration of petitions. As such, in its final Report the CSG states that:

"It is important to enable groups and individuals to influence the Parliament's agenda. We looked at a number of models in other Parliaments for handling petitions and concluded that the best of these encouraged petitions; had clear and simple rules as to form and content; and specified clear expectations of how petitions would be handled... We propose the establishment of a dedicated Petitions Committee."

The CSG also set up an Expert Panel on Information and Communications Technologies (ICT) whose remit included considering: 'how can ICT assist the realization of the Parliament's aim of promoting democratic participation, including community governance and citizen participation?' While e-petitioning was not considered by the CSG it should nevertheless be viewed as a direct response to the overall aims of the CSG especially within the context of encouraging democratic participation. This is a view shared by Coleman et al (2002) who argue:

"If technology is regarded as possessing autonomous qualities that can remedy the ills of democracy, it is bound to let us down; but if it can be utilised in the service of creative politics to make democratic politics more accessible, accountable and inclusive, there is real scope for the reinvigoration of governance."

The partnership between the Scottish Parliament and the ITC at Napier University began in December 1999 when the PPC agreed to allow an internet-based petition from the Centre's web site sponsored by the World Wide Fund for Nature to be the first electronic petition to collect names and addresses over the internet, eventually attracting 309 signatures and 9 
comments. The PPC subsequently agreed to allow groups and individuals to submit e-petitions, and on the 14 March 2000 the Committee accepted its first e-petition. This was a historical event as the Scottish Parliament became the first statutory body to formally accept e-petitions. Indeed, the Scottish Parliament is a recognised world leader in e-participation and:

"Few countries have used technology to enable electronic petitioning to the extent of the Scottish Parliament." (OECD, 2004)

The PPC primarily provides an opportunity for individual members of the public to participate fully in the democratic process in Scotland by raising issues of public concern with the Parliament. However, there are no restrictions on who can submit a petition or the number of signatures required for a petition to be considered. The Committee has in its first six years considered over 800 petitions on a bewildering range of topics from every corner of Scotland.

The Committee is widely regarded as being relatively successful in enhancing participation in the political process. For example, the Scottish Civic Forum state that the Committee:

"Has scored notable successes in allowing people from all over Scotland to participate, and in stimulating legislation on issues that are important to certain communities but might find it difficult to get attention in the normal sweep of executive policy making."

This success is also reflected in the feedback which the Committee has received from petitioners themselves. For example, as stated by a petitioner in the recent Health Committee public debate in the Parliament:

"The people of Scotland should be well proud of this institution and of the fact that when ordinary people sign a piece of paper on the street and ask me whether it will make a difference, I can look them in the eye and say, "Yes, this can make and is making a difference."

This petitioner lodged an e-petition on the provision of consultant-led acute services in rural communities which attracted 1906 signatures on the website and 89 comments on the discussion forum. The petition was subsequently referred to the Health Committee for its consideration.

The PPC is keen to promote the public petitions system including epetitioning especially among groups traditionally marginalized from the political process. Therefore it has agreed a rolling programme of committee events aimed at providing practical advice and guidance to local community organizations across Scotland on petitioning and e-petitioning.

The PPC's role is to ensure that appropriate action is taken in respect of each admissible petition submitted and, in fulfilling this function, the 
Committee takes responsibility for the initial consideration of the issues raised. It is not for the Committee to make recommendations in relation to the substantive issues arising from petitions but rather to assess whether a petition raises issues which would merit further consideration by the Parliament. If so, the Committee would generally formally refer a petition to the relevant subject committee. This generally involves hearing evidence from many petitioners in support of their petitions, conducting background research and seeking comments from key stakeholders on the issues raised in the petition. Ministers and public body representatives may also be called to appear before the Committee to supplement the information provided in their written responses.

\section{THE E-PETITIONER SYSTEM}

The e-Petitioner System comprises 2 sections:

- The Front-End - the publicly accessible web pages where the citizens interact with the system;

- The Back-End - the private Administrative Section which comprises password protected web pages for all administrative functions.

\subsection{The Front-End}

The Front-End provides citizens with 10 basic e-petition functions:

1. About e-Petitions: provides an overview of how to e-petition the Parliament and gives guidance on petitioning.

2. Download e-Petition Template: provides a downloadable template for construction of an e-petition. E-petitions must be submitted using this.

3. List All e-Petitions: lists the e-petitions along with the name of the individual or organisations who originally raised the petition and the current status of the petition.

4. View/Sign Petition: this is the main e-petition page. It contains the name of the person who originally raised the petition, 'the petition text', and the 'sign petition' facility. Here a user who agrees with the petition issue can add their name and address to the petition. The user is requested to provide a full postal address including postcode and country. The postcodes and countries are summarised and used in the brief to the Parliament. There is also a data protection statement detailing how the gathered information will be used, and there is a summary of the petition details, including how many people who have signed by that date, how many comments have been posted in the discussion forum, and a list of the 5 most recent signatures. 
5. Post Signing Questionnaire: is an online evaluation questionnaire to monitor what users think of the system. It provides a way for the Parliament to assess user reaction.

6. View Signatures: lists the names, along with their countries, of all those who have signed the e-petition. Giving any further details of signatories would breach the Data Protection Act.

7. Background Information: this shows additional information, provided by the principle petitioner, which supports the petition and allows the users to be better informed about the petition issue.

8. Discussion: provides users with the opportunity to comment further on the petition and to generally discuss issues raised by the petition.

9. Tell a Friend: is an emailing facility for users to inform others about the petition.

10. Progress in Parliament: links to the Parliament's main petitions page, giving the number of the submitted petition so as to allow tracking of the petition through its life in the Parliament.

\subsection{The Back-End}

The Back-End provides 5 high-level commands through which either the parliamentary staff or members of the ITC can support and maintain the epetitioning processes. These are:

1. Edit e-Petition: allows the petition details, such as closing date and status to be easily amended.

2. Create e-Petition: this is where a new petition is created on the website from a submitted e-petition template.

3. Discussion: houses all of the moderation facilities for the integrated discussion forum, including: adding any moderation comments; pulling together all the comments to produce an overall report; and viewing statistics - such as the number of times a comment has been viewed.

4. Questionnaire: displays the results of the evaluation questionnaire.

5. Signatures: displays the full address details of those who have signed the e-petition. It allows a mailing list to be created of those who said they were willing to have their email contact details added to this, and also allows administrators to remove invalid signatures from the public site.

Given that accessibility is a key aspect of the system, recent advances in web accessibility technologies are integrated wherever possible, and the current release of the e-Petitioner System is consistent with the Web Access Initiative's (WAI) Level 2 compliance specifications.

The signatures on an e-petition are simply the name and location given by a citizen who wishes to support a petition. While it would be technically 
possible to require citizens to provide digital signatures, that would be inconsistent with the objective of maximising accessibility since it would add to the technical competences required of citizens.

Duplicate names and addresses can occur, either through accidentally submitting the sign petition form more than once, or a person may sign a petition on multiple occasions. These are monitored and automatically marked as duplicates by the software.

Bogus signature or address detection could be automated, but experience of operating the e-Petitioner System over a number of years has shown it to be very difficult to do reliably - for example the most obvious mechanism of blocking multiple signatures from the same IP address can preclude legitimate signatures from different people within a single organisation (which may post only a single IP address), and can also be easily defeated by someone repeatedly using a dialup connection, where IP addresses are usually dynamically assigned - so developing facilities to enable manual moderation of signatures from within the administration section assisted by metrics has been preferred. These help identify any possible discrepancies, that could occur, but it is pertinent to note that Scottish Parliament set no minimum signatures requirement for a petition to be considered, thus there is little incentive for lobbying groups to fake e-petition signatures.

The e-Petitioner System is a dynamic website implemented in Active Server Pages. VBScripts generate the HTML, access and update the petition data. This data is maintained in a SQL Server relational database, with the exception of petition background information, which is stored to disk.

\section{THE E-PETITIONER PARLIAMETNARY PROCESSES}

The e-Petitions System within the Scottish Parliament should not be viewed as separate to the traditional paper method of petitioning but as an alternative method or supplementary method of gathering support for the aims of a petition through ICTs. The e-Petitioner System allows a petition to be hosted on the Parliament's website for an agreed period providing an opportunity to attract a wide audience and gather names in support of the petition. The petitioner may wish to use this method solely in gaining support or may wish to use it in addition to traditional face to face gathering of signatures. There is space for supporting information so that the issue can be placed in context, and each e-petition also has its own discussion forum where visitors and signatories can discuss the petition and surrounding issues online. The forum gives everyone the opportunity to comment further on the petition. They can make comments either for or against the petition and 
everyone can read their comments and reply to them. Having an integrated discussion forum as part of the petitioning process is important as it makes the process much more interactive and allows a constructive debate to occur on the issue. Those in favour have opportunity to provide further detail as to why they support the issue, and those against have an important opportunity to say why the petition should not go ahead or how it should be modified.

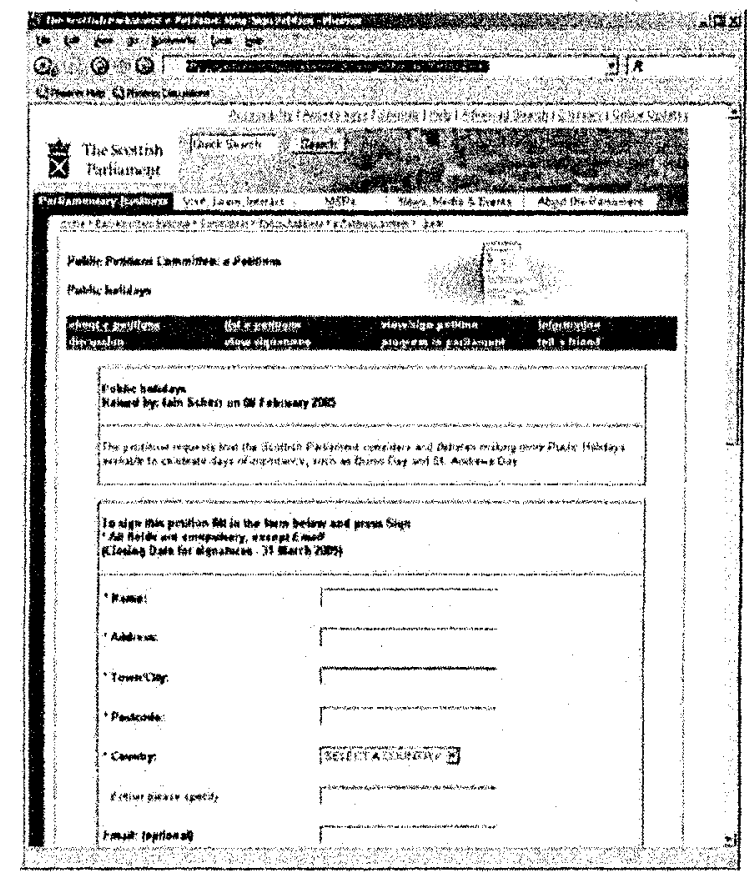

Figure 1. An example of an e-petition on the Scottish Parliament e-Petitioner System.

Unlike the e-petitions process introduced by the legislative Assembly of Queensland there is no requirement for an e-petition to be sponsored by a Member of the Scottish Parliament. Ordinarily a person (or organisation) wishing to raise a petition would contact the PPC clerking team and agree with them the text for the petition. This is necessary to ensure the petition is admissible within the Guidance on the Submission of Public Petitions ${ }^{1}$.

While petitions are generally driven by a specific local issue such as a planning matter or closure of a school, the Committee has no remit to be involved in such issues which are essentially matters for the relevant local authority. Rather, the primary locus of the Committee is to hold the Scottish Executive to account and, therefore, petitions are required to identify which action they would like the Scottish Executive to take. This will generally take the form of calling for a review or change to Scottish Executive policy 
at the national level. This process supports both paper and electronic petitions, but as our interest is in the latter we shall only consider it here.

Once the text of the e-petition has been agreed, it is then entered into the e-Petitioner System through a form in the online administration section. In addition to the petition text, supporting information and further details on the Principal Petitioner can be added. This process also adds the petitioner's name as the first signature on the e-petition, and submits their supplied comment to the discussion forum for the petition to initiate debate.

The petition is then live and run for the prescribed period (usually 4-6 weeks), during which the signature list is regularly checked for spurious signatures, and the discussion forum moderated daily by the PPC clerking team. In particular, comments are checked to ensure that they are relevant to the aims of the petition and not potentially defamatory or inflammatory.

At the completion of this period the petition is closed, and a briefing paper is generated providing some analysis of the geographical breakdown of signatories and a summary of the discussion comments, and passed along with the list of signatures to the Principal Petitioner. They then decide whether they wish the petition to go further, and if they do then it is formally lodged by the PPC clerking team and published in the Business Bulletin and on the Parliament's website with a petition number, for example, PE100.

Such a petition is then considered at a meeting of the Public Petitions Committee where the petitioner may be invited to give evidence to the Committee. The Committee's annual report for the year ending 6 May 2005 indicated that the Committee considered 110 new petitions (of which 29 were e-petitions) and heard from 51 petitioners, so around half of all petitioners are invited to give evidence to the Committee.

An important aspect of the public petitions system in line with the CSG's emphasis on openness and transparency is that petitioners are advised of the progress of their petition at all stages of its journey through the system and that other interested parties may monitor this progress through each petition's feedback page on the website. The link between each e-petition and the relevant feedback page allows anyone to easily find out any subsequent action which occurred in relation to a petition. This completes the petitioning process.

\section{CURRENT STATUS IN THE SCOTTISH PARLIAMENT}

In the current session of the Scottish Parliament (from September 2003 to date) 45 e-petitions have been raised on a number of issues ranging from 'supporting an investigation into Scottish football', 'Broadband for all of 
Scotland by 2005 ' and 'support for a global campaign for education'. See http:/lepetitions.scottish.parliament.uk/list_petitions.asp. The majority of the e-petitions have been raised by individuals or community groups who have come together specifically to support the petition issue.

In this respect it is clear that the e-Petitions System has contributed to the aims of the CSG in enabling 'groups and individuals to influence the Parliament's agenda'. While there will inevitably be some debate as to whether this amounts to 'sharing the power' there is no doubt that it does encourage a more participatory role for Scottish citizens and lend some credibility to the notion that it is their Parliament. In this context the PPC has also taken steps to address equalities issues in its work with the aim of increasing awareness among all sections of Scottish society of the petitions processes. For example, the PPC has endorsed the Equal Opportunities Committee guidelines on mainstreaming equality in the work of parliamentary committees, introducing an equal opportunities monitoring form. They have also published guidance on the submission of petitions in: English, Arabic, Bengali, Cantonese, Gaelic, Punjabi and Urdu and Braille, with audio versions also available.

Petitions can be lodged in any language and the Parliament accepted its first non-English e-petition on 16 April 2004. This petition calling for the standardisation of school holidays in Scotland was lodged in Gaelic with an English translation. The representative nature of the e-Petitions System is also reflected in the range of issues which have been raised as e-petitions. For example, in relation to local transport for Scotland's disabled people, speech and language therapy services and calling for a public inquiry into the increase in autism.

A total of 20,812 signatures have been added to the petitions and 639 discussion comments have been posted. The most successful in terms of signatories is an e-petition calling for an investigation into the 'Upgrade of the A90 trunk road in Aberdeenshire' which collected 2606 signatures and 47 comments.

The e-Petitions System also provides the opportunity for petitioners to gather support for their petition globally. For example, the e-petition 'Culture and tourism policies regarding Robert Burns' ran over a 6 week period and collected a total of 1810 signatures. Although the majority, 1000, were from Scotland; 260 were from the United States; 144 from Canada; 142 from England; and the remainder from a further 35 countries ranging from Poland to Brazil. This information is provided in a briefing pack to the PPC and is useful in demonstrating the breadth of support for a specific issue.

When the e-Petitioner System was first launched, few citizens appreciated how the discussion forum could be used to support their cause. These early e-petitions typically received 1 or 2 comments. That situation 
has gradually changed and now users see the discussion forum as a means to tell their own story of how they have been affected by policy (or lack of it). For example, a petition raised in July 2004 requesting "that the Scottish Parliament urge the Scottish Executive to ensure the provision of acute $24 \mathrm{hr}$ a day all year round consultant-led services across Scotland, including rural communities" received 89 comments from 1906 signatories. Comments such as the following were received:

"Our Grandmother lives in Fort William and we visit Fort William a lot, and we have heard everyone talking about how important it is to have consultancy services in the Belford. We also know what is happening in PRI in Perth and think it is awful."

and

"My wife underwent major surgery at the Belford recently and we have only praise for the care, skill and dedication of the staff. The Belford is a major asset of the West Highlands and it is important that the expertise it offers remains accessible to the locality."

The discussion forum is helping to further the aims of the CSG in developing a 'culture of genuine consultation and participation' and encouraging communities who were previously excluded from the political process to participate in the work of the Parliament.

In increasing the level of participation, the e-Petitions System is also enhancing the accountability of MSPs. The CSG states that: 'The Scottish Executive should be accountable to the Scottish Parliament and the Parliament and Executive should be accountable to the people of Scotland' (HMSO, 1999:7). Here petitions allow the public to raise issues which otherwise might not be addressed by the politicians or encourages them to return to issues which have been considered previously, and the PPC in pursuing petitions on behalf of petitioners may then ensure the relevant Minister is held to account in relation to the policy issues addressed by it.

\section{MONITORING THE E-PETITIONER SYSTEM}

Visitors to the e-Petitioner site who choose to add their name to a petition are presented with an 'exit questionnaire'. This facilitates a degree of monitoring of what users think of the system, and is a way to assess user reaction. As the exit questionnaire is voluntary it has been completed by only 1,214 of the 20,812 e-petition signers - just under $6 \%$. The table gives an overview of some of the responses to a few of the questions.

The final question asked is "Is there anything you think we should change about e-Petitioner?" Here there were a large number of open 
responses, the majority of which indicated there were no serious problems.

\begin{tabular}{|l|l|l|l|c|}
\hline Question & $\begin{array}{l}\text { Highest } \\
\text { response }\end{array}$ & Percent & $\begin{array}{l}\text { Second } \\
\text { highest }\end{array}$ & Percent \\
\hline $\begin{array}{l}\text { Where have you been } \\
\text { using this website today? }\end{array}$ & $\begin{array}{l}\text { From } \\
\text { home }\end{array}$ & $67.92 \%$ & $\begin{array}{l}\text { From } \\
\text { work }\end{array}$ & $24.63 \%$ \\
\hline $\begin{array}{l}\text { Did you require help with } \\
\text { this website? }\end{array}$ & No & $96.48 \%$ & Yes & $2.78 \%$ \\
\hline $\begin{array}{l}\text { Did you find that signing } \\
\text { the petition was ... }\end{array}$ & $\begin{array}{l}\text { Easy } \\
\text { enough }\end{array}$ & $97.71 \%$ & Not sure & $0.98 \%$ \\
\hline $\begin{array}{l}\text { Did you find reading the } \\
\text { info provided was ... }\end{array}$ & $\begin{array}{l}\text { Easy } \\
\text { enough }\end{array}$ & $95.74 \%$ & $\begin{array}{l}\text { Didn't } \\
\text { look at it }\end{array}$ & $1.72 \%$ \\
\hline $\begin{array}{l}\text { Could you see yourself } \\
\text { using this website again } \\
\text { for other petitions? }\end{array}$ & Yes & $81.34 \%$ & Not sure & $16.28 \%$ \\
\hline
\end{tabular}

The results will not include any site users who visited but found ePetitioner either uninteresting or too difficult to use, since they will not have signed an e-petition, so cannot be solely used as a basis for comprehensive evaluation, but the results make a valuable contribution, and were helpful for the process of deploying e-Petitioner in other arenas. An in-depth evaluation $^{2}$ of e-Petitioner took place in March 2001. This involved semistructured interviews and participant observations. Petitioners indicated that they viewed e-Petitioner as a useful tool in influencing politicians. The ability to access at a convenient time and reach wider sections of society made possible by e-Petitioner were considered inherently more democratic.

In terms of access to the system, e-Petitioner is a widely used resource with some 30,594 visitors to the site staying 147 seconds and viewing 3.55 pages on average, during the 6 month period up until $30^{\text {th }}$ April 2005 .

\section{TRANSFERABILITY}

In Spring 2004, Office of the Deputy Prime Minister (ODPM) of the UK Government initiated a National Project for Local e-Democracy to explore how ICT can change the way in which public authorities engage and work with Citizens (http://www.edemocracy.gov.uk/default.htm). As part of the initiative the ITC was invited to develop and evaluate a version of ePetitioner to run in two local authorities. The project aimed to explore epetitioning as a way for citizens to raise their own concerns within the formal processes of the local authority. E-petitioning was implemented and

\footnotetext{
${ }^{2}$ http://itc.napier.ac.uk/ITC_Home/Documents/e-petitioner_Rowntree_evaluation.doc
} 
piloted by the Royal Borough of Kingston upon Thames who led the project, and Bristol City Council. The development of e-petitioning in the National Project stemmed from the experience of the Scottish Parliament and both Councils acknowledge how their use of the system has been derived from the Scottish Parliament's guidelines.

The ITC worked alongside the Councils' e-Democracy project managers to localise the e-Petitioner tool and embed it in their processes for handling petitions, while ensuring it remained sufficiently generic to be easily adapted to the needs of other Councils. In Kingston this work was coordinated through the IT Department, and in Bristol through the Corporate Consultation team. As well as deploying the system and developing procedures to handle e-petitions, the Councils' role included promoting the system internally (to Councillors) and externally (to members of the public).

Local authorities, by contrast, are much smaller entities than a Parliament, and have far fewer resources. So, frequently, in carrying out their core responsibilities of outworking the legislation created by the national Parliaments at a local level they find little left over to resource a formal petitions procedure. Consequently the petitions processes at Local Authority level tend to be less well defined. Often petitions cluster around a small number of departments in the Council, of which Planning is usually the most popular. Over time such departments would have devised their own processes for dealing with petitions, while many less frequently petitioned departments may have no processes at all.

Thus the first task in establishing the e-Petitioning System within a Local Authority is to formally define a petitions process that it suitable to their context. In Kingston, developing the e-petitioning process entailed a need to publish guidelines for the first time, and to put in place a mechanism for managing new e-petitions, as well as updating the site and publishing the Council's formal response to each petition. The addition of a new 'channel' for petitioning and the associated need to guide website visitors on how they might use it, established the case for publishing guidelines on petitioning in general. The Kingston e-Petitioner System ${ }^{3}$ is shown in Figure 2.

As can be seen the e-Petitioner site is a 'localised' version of the system already operational on the website of the Scottish Parliament. The main effort in transferring the system lay in meeting the need for easy to use administration functions, in meeting accessibility requirements (Web Accessibility Initiative, 2004) which are now mandatory, and in providing a more modular architecture suited to the need for the software to be tailored to the varying needs of local authorities. The Scottish Parliament ePetitioner System is maintained by ITC as a 'managed service', an

${ }^{3}$ See http://e-petitions.kingston.gov.uk/. The Bristol City Council e-Petitioner is available at: http://www.bristol-city gov.uk/item/epetition.html 
arrangement that could not meet the needs of the National Project tools to be sustainable beyond the life of the project. Kingston and Bristol required facilities for their own officers to administer their respective systems.

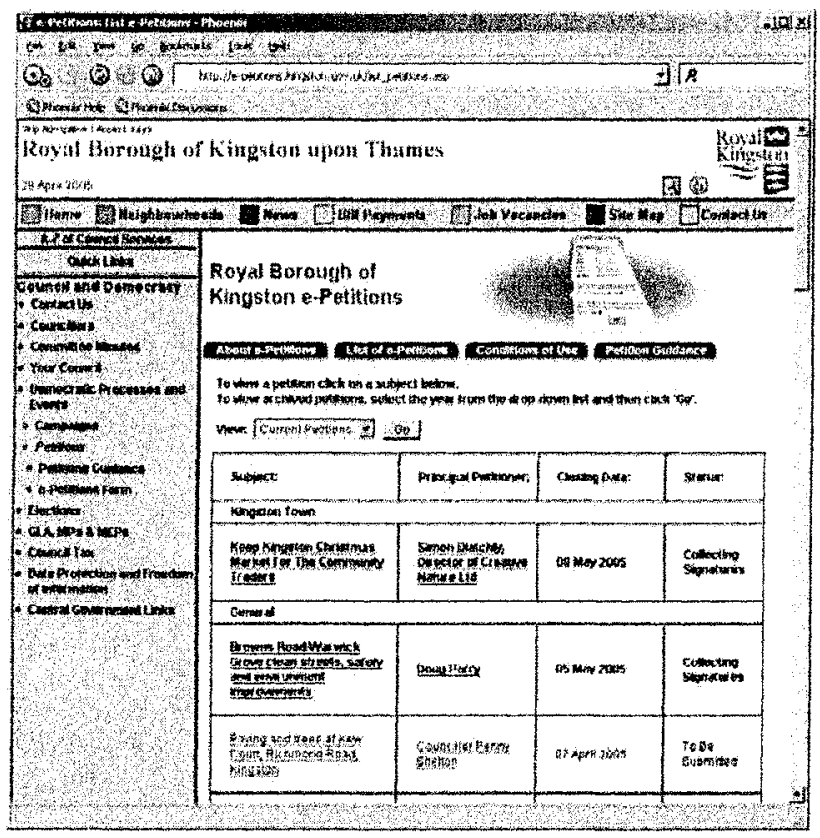

Figure 2. Listing Petitions in the Royal Borough of Kingston e-Petitioner System.

At the end of the pilot period (17 March 2005) an evaluation was undertaken (Whyte et al., 2005). Over the period of the pilot there were 7 epetitions for Kingston, and 9 paper petitions were presented to the Council in the same period. In Bristol there were 9 e-petitions and 22 on paper. The total number of e-petition signatures was 173 in Kingston and 890 in Bristol.

Citizens, Officers and Members who took part in the evaluation were almost unanimously in favour of e-petitioning. It has enjoyed strong support from Councillors in both Kingston and Bristol, particularly Kingston, and from the departments who are directly involved in the day-to-day servicing of representative government. The issues raised through e-petitioning are unarguably issues that are important to citizens, and are evidently addressed through local authority decision-making. E-petitions were raised on, for example, road crossings, telecoms masts, and Post Office closures. The ePetitioning pilot has increased transparency in part by formalising the process for handling petitions for the first time. The publication of the site and its associated guidelines on petitioning makes both the process and the petition outcomes more visible. The added visibility applies to paper as well as e-petitions, since paper petitions that are presented at Council meetings are also listed on the e-Petitioner page. The evaluation states: 
"The evaluation found much had been accomplished in both Councils. Over the one year project lifetime staff were recruited, the supplier contracted, e-Petitioner implemented, working practices and processes examined and the tool launched to be used by the public. E-Petitioner was used by hundreds of citizens in each Council area, and showed early signs of impacting on decision-making."

\section{CONCLUSION}

The Scottish Parliament's e-Petitions System has led the way in offering citizens the possibility of a more active interaction with the political process which is readily accessible and transparent and provides a direct means of holding elected politicians to account other than through the ballot box.

We have seen how the System has attracted growing interest from the Public to the point that to date in the current Session there have been a total of 20,812 signatures and 639 discussion comments made through the System, and perhaps its most telling selling point is that there are increasing signs that it is having an impact on the policy process within the Parliament.

The wealth of experience gained through operating the e-Petitioner System successfully at a national level has been seen to have facilitated the re-engineering of the System for the needs of Local Authorities, and through case studies on two English Local Authorities where e-Petitioner was deployed, are seeing early signs that e-Petitioner is a useful tool in enabling citizens to better engage with political processes at a local level also.

\section{REFERENCES}

Coleman, S., with Hall, N., and Howell, M. (2002), Hearing Voices: The Experience of Online Public Consultations and Discussions in UK Governance, Hansard Society. HMSO (1999), Shaping Scotland's Parliament, Report of the Consultative Steering Group.

Macintosh, A., Malina, A., and Farrell, S. (Scottish Parliament) (2002), Digital Democracy through Electronic Petitioning; In McIver, W., and Elmagarmid, A.K. (eds). Advances in Digital Government: Technology, Human Factors, and Policy, Boston/Dordrecht/London, Kluwer Academic Publishers, pp 137-148.

OECD (2001), Citizens as Partners: Information, Consultation and Public Participation in Policy-Making, OECD, Paris.

OECD (2004), Promises and Problems of e-Democracy; Challenges of Citizen on-line Engagement, OECD, Paris.

The Electoral Commission (2005), An Audit of Political Engagement 2, Research Report March 2005. ISBN: 1-904363-60-1.

Web Accessibility Initiative (2004), Web Content Accessibility Guidelines 2.0, World Wide Web Consortium. Available at: http://www.w3.org/WAI/.

Whyte, A., Renton, A., and Macintosh, A. (2005), e-Petitioning in Kingston and Bristol: Evaluation of e-Petitioning in the Local e-Democracy National Project, Improvement and Development Authority, London. (Forthcoming) 